\title{
Encapsulation method developed for OLED devices mounted at laboratory
}

\section{Método de encapsulamento desenvolvido para dispositivos OLEDs montados em laboratório}

\author{
Emerson Roberto Santos ${ }^{1,2, \star}$ (D), Erik Yassuo Yuki ${ }^{1}$, Wang Shu Hui ${ }^{1}$ (D) \\ 1. Universidade de São Paulo - Escola Politécnica - Engenharia Metalúrgica e de Materiais - São Paulo (SP), Brazil. \\ 2. Laboratório SuperCriativo - São Paulo (SP), Brazil. \\ Correspondence author: emmowalker@yahoo.com.br \\ Section Editor: Maria Lúcia P Silva
}

Received: Dec. 13, 2020 Approved: Jan. 26, 2021

\begin{abstract}
A simple method with low cost of encapsulation for organic light emitting diode (OLED) devices mounted at laboratory was proposed to obtain considerable increase of the lifetime. In this study, it was used a capsule formed by: glass slide as substrate, a layer of polyvinyl acetate glue diluted in methyl alcohol, a layer of calcium oxide as secant and epoxy placed at the edges of capsule. The performance of this capsule was analyzed using a thin film of polymer semiconductor called as PEDOT:PSS, that is sensitive to moisture and oxygen from atmospheric air. The PEDOT:PSS thin layer was deposited between anode and cathode electrodes using commercial indium tin oxide (ITO) thin film deposited on glass substrate. The capsule was placed covering completely the PEDOT:PSS thin film, and the electrical resistance was measured by elapsed days. This result revealed lowest electrical resistance compared with other methods, showing also good performance as encapsulation process.
\end{abstract}

KEYWORDS: Moisture, Oxygen, Encapsulation, Degradation, Organic light emitting diode, PEDOT:PSS.

\begin{abstract}
RESUMO
Um método simples e de baixo custo para encapsulamento de dispositivos de diodo orgânico emissor de luz (OLED) montados em laboratório foi proposto para obter considerável aumento do tempo de vida. Neste estudo foi usada uma cápsula formada por: lâmina de vidro como substrato, camada de cola de acetato polivinil diluída em álcool metílico, camada com óxido de cálcio como secante e epóxi colocada sobre as bordas da cápsula. O desempenho dessa cápsula foi analisado utilizando um filme fino polimérico semicondutor chamado de PEDOT:PSS, que é sensível à umidade e ao oxigênio do ar atmosférico. A camada fina de PEDOT:PSS foi depositada sobre eletrodos de anodo e catodo utilizando filme fino de óxido de índio e estanho (ITO) depositado sobre substrato de vidro. A cápsula foi colocada cobrindo completamente o filme fino de PEDOT:PSS, e a resistência elétrica, medida pelo decorrer dos dias. O resultado revelou mais baixa resistência elétrica se comparado com outros métodos, mostrando também bom desempenho como processo de encapsulamento.
\end{abstract}

PALAVRAS-CHAVE: Umidade, Oxigênio, Encapsulamento, Degradação, Diodo orgânico emissor de luz, PEDOT:PSS.

\section{INTRODUCTION}

Devices known as organic light emitting diodes (OLED) have been investigated largely in the last decade, due to its easy method of fabrication and large potential of applications ${ }^{1,2}$. For this reason, some studies have been reported in the literature showing large variability of color emission obtained from different materials ${ }^{3-5}$. In the past, the first monochromatic OLED device was used in car stereo by Pioneer Company in 1997, and OLED 
device with a totally colorful display was used in a digital camera manufactured by Eastman Kodak Company, model EasyShare LS633, in 20036. This model was considered as the first digital camera manufactured in mass with totally colorful organic display. From past to present, the industry of consumer electronics has considerably increased the use of the OLED technology as displays for some devices as smartphones, TVs and smartwatches ${ }^{7}$, but the lifetime of OLED devices is still a limit factor for its use by long time demonstrating a necessary improvement of encapsulation technology (mainly for devices mounted at universities, colleges and research institutes) $)^{8,9}$.

In literature, efficient methods of encapsulation can be found involving complex techniques of microelectronic using large and very expansive sophisticated equipments ${ }^{10-12}$. Because of that, an efficient method of encapsulation has an expensive cost. Then, an easy manual procedure with low cost for OLED devices encapsulation was developed to be used at laboratory ${ }^{13,14}$. Some encapsulation methods used by companies have been reported. However, there are no more details about them. An example of OLED encapsulation developed by Osram Company is showed in Fig. 1, revealing a thin film of encapsulation, glass and glue, but it does not point out all specific materials used ${ }^{15}$. This company reports the use of glass in the final step of encapsulation.

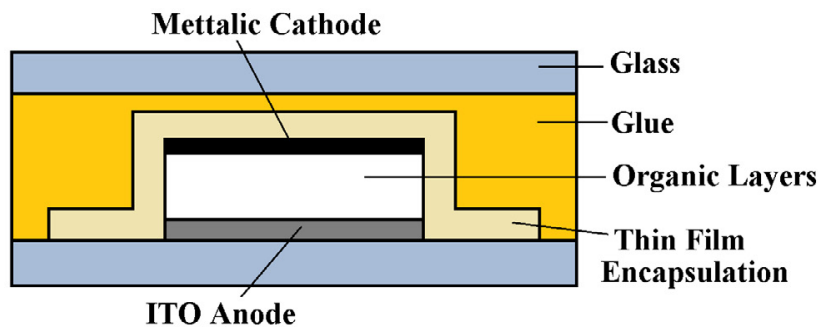

ITO: indium tin oxide.

Figure 1: Method of organic light emitting diode (OLED) device encapsulation manufactured by Osram Company ${ }^{15}$.

Moreover, glass has bad permeation to the moisture and oxygen, and for this motive it is largely used as a barrier protecting the active area of the OLED devices. The thickness of glass is very important, since it must offer sufficient physical resistance 16,17. The Osram Company does not report the thin films used to the encapsulation method (Fig. 1), but in literature two different materials deposited, as organic and inorganic films ${ }^{18}$, are found.

The permeation in materials can be described by Eq. $1^{19}$ :

$$
P=D \cdot S
$$

in which: $P$ = the permeation coefficient; $D=$ the diffusion rate; $S=$ the solubility.

The permeation is generally represented by transmission rate $(T)$, that is the amount of a gas which crosses two parallel surfaces of a material by elapsed time. The permeability (G) is the transmission rate divided by the difference of partial pressure $(\Delta p)$ on each side of the film (organic or inorganic). The permeability coefficient is the product of the permeability and the film thickness (d) (Eqs. 2 and 3) $)^{19}$ :

$$
\begin{gathered}
P=G \cdot d \\
P=(T / \Delta p) \cdot d
\end{gathered}
$$

in which: $G=$ the permeability; $d=$ the thickness of the film; $T=$ the transmission rate; $\Delta p=$ the partial pressure; $d=$ the thickness film.

Figure 2 shows the lowest permeation of the oxygen and water vapor to the OLED devices compared with other processes $^{19}$. 


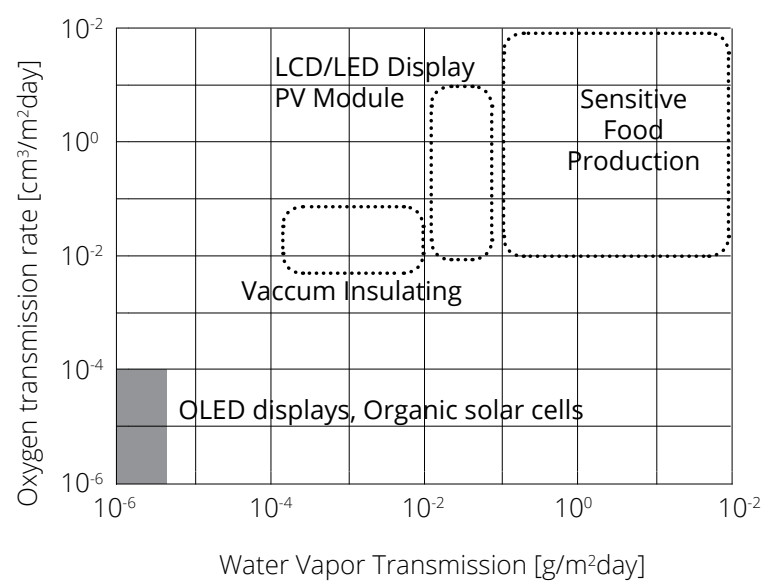

LCD: liquid crystal display; LED: light emitting diode; PV: photovoltaic; OLED: organic light emitting diode.

Figure 2: Transmission rates to oxygen and water vapor for some applications, including commercial organic devices ${ }^{19}$.

The mechanism of permeation in inorganic film as a barrier is dominated by a concentration of defects. Due to the difficulty of creating defect-free using thickness from 50 to $200 \mathrm{~nm}$ usually for encapsulation, researchers found an option using multi-layer structures ${ }^{20}$. To improve the process encapsulation in OLEDs industry, several intercalated layers are used with organic and inorganic materials forming multi-layer structures with misalignment of defects and creating a tortuous path to difficulty the diffusion of degradation ${ }^{13}$. The lifetime of OLED devices depends on the emitting material used and on the conditions of polarization, but blue light emission has presented the lowest performance when compared with emission of other color ${ }^{21}$.

\section{Encapsulation method at laboratory using epoxy adhesive and glass lid}

Four OLED devices have been mounted at the same time on each blade with geometry of $2.5 \times 2.5 \mathrm{~cm}$. A method of low-cost encapsulation has been used at laboratory with epoxy (dried at 10 minutes) stripe at the edge of a glass lid. This glass lid was put on the blade covering all active areas with geometry of $3 \times 3 \mathrm{~mm}$ of OLED devices2 ${ }^{22}$. Figure 3 shows an OLED device turned-on with epoxy and glass lid (with black drawn detail) covering all OLED devices.

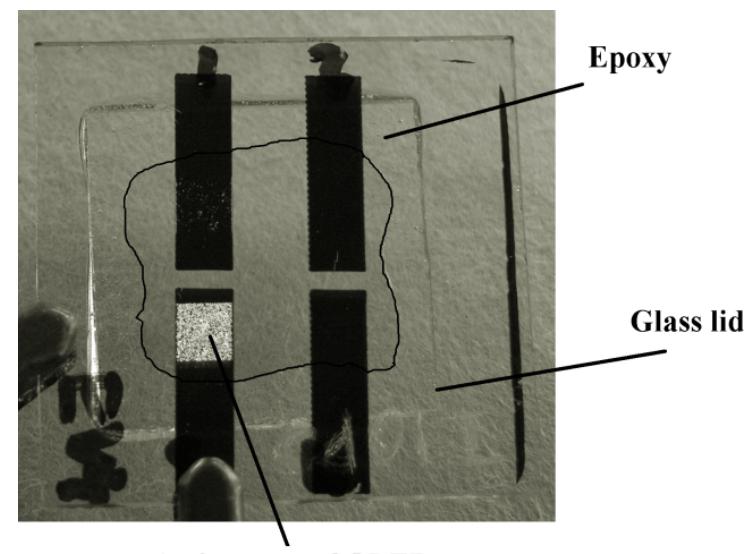

Active area of OLED

OLED: organic light emitting diode.

Figure 3: Blade with four OLEDs encapsulated with epoxy adhesive and glass lid covering all devices.

In this encapsulation process, the epoxy has spread near the active area causing damage, as evidenced by Fig. 4, obtained with $20 \times$ magnification by optical microscope. This considerable fact accelerates the degradation process of the active area decreasing the performance of the OLED device. 
This encapsulation procedure needs to be performed inside the glove box system under inert atmosphere (with nitrogen or argon) to avoid the exposure of the OLED devices to the oxygen and moisture from atmospheric air23,24.

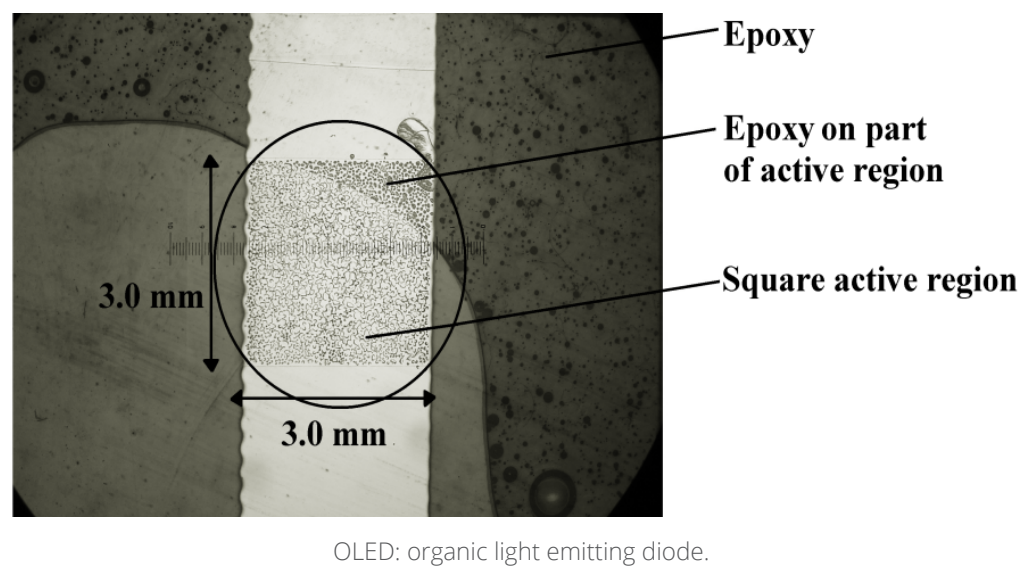

Figure 4: Active area of OLED device turned-off with epoxy adhesive part on the emissive region.

\section{Encapsulation method at laboratory using epoxy adhesive, glass lid with cavity and secant powder}

Another encapsulation method as degradation barrier has been used with glass lid cavity and also with calcium carbonate (CaCO3) powder as secant ${ }^{25}$. In the glass lid, there is a cavity to the deposition of secant, and this capsule is pressed on all active regions of OLED devices. Inside the little cavity, some material is necessary to hold the secant powder, and in this case it was used a double-sided tape. Then, the glass lid with the secant and epoxy at the edges was put on the active areas. Figures 5A and 5B show the schemes involving this complete process developed by Daniela Diodato de Magalhães ${ }^{25}$. The cavity on glass lid was carried out using hydrofluoric acid (HF), involving a slow process.

(a)

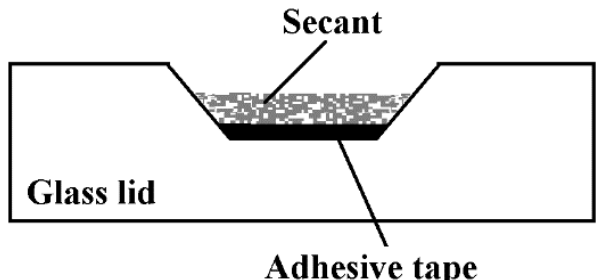

(b)

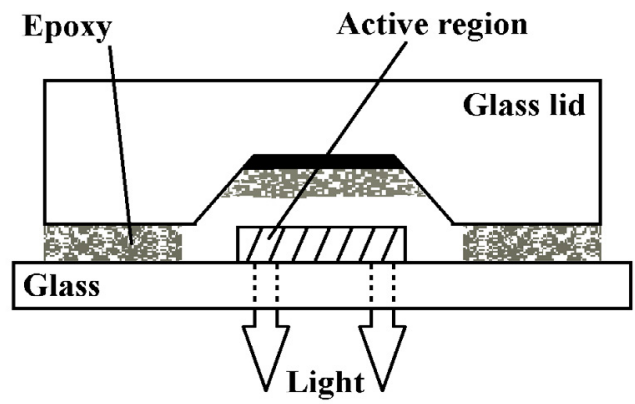

OLED: organic light emitting diode.

Figure 5: (a) Structure containing: glass lid with cavity, secant with double-sided tape; (b) active region of OLED device completely isolated from atmospheric air.

The results found by Daniela Diodato de Magalhães showed good advantages to the encapsulation method of OLED devices mounted at laboratory, allowing extended lifetime and improving the emission of light, but this process also revealed the necessity to find an easier alternative method ${ }^{25}$.

\section{MATERIALS AND METHODS}

In this work, a different structure of encapsulation was proposed using glass lid, epoxy and calcium oxide (CaO) powder as secant ${ }^{26}$. This structure was tested to cover a polymeric thin film susceptible to chemical attack by moisture and oxygen from atmospheric air. 
Firstly, a CaO layer was deposited on glass by spin-coating technique. After that, at the edges of glass lid an epoxy stripe was deposited.

The materials used in the structure were: glass blades (with geometry of $2.5 \times 2.5 \mathrm{~cm}$ ), glue composed by polyvinyl acetate (PVA), methyl alcohol, epoxy (dried by 10 minutes), CaO powder, pipette, nitrogen gas, double-sided type, hard disk disassembled with nominal speed of 5,400 rpm (as spinner) and source power.

Three main objectives were required in the assembly of the structure: to obtain a thin film of PVA glue on the glass blades, to cover the PVA layer with secant material $(\mathrm{CaO})$ and to prevent the physical contact of secant with the polymeric layer.

\section{Preparation of the structure}

Initially, commercial PVA with $5 \mathrm{~mL}$ was diluted in $20 \mathrm{~mL}$ of methyl alcohol and deposited on glass lid using a hard disk (obtained from a microcomputer), to form a layer with good uniformity ${ }^{27}$. Firstly, the surface of disk was moistened and covered by plastic foil. Figures 6A and 6B show this process.
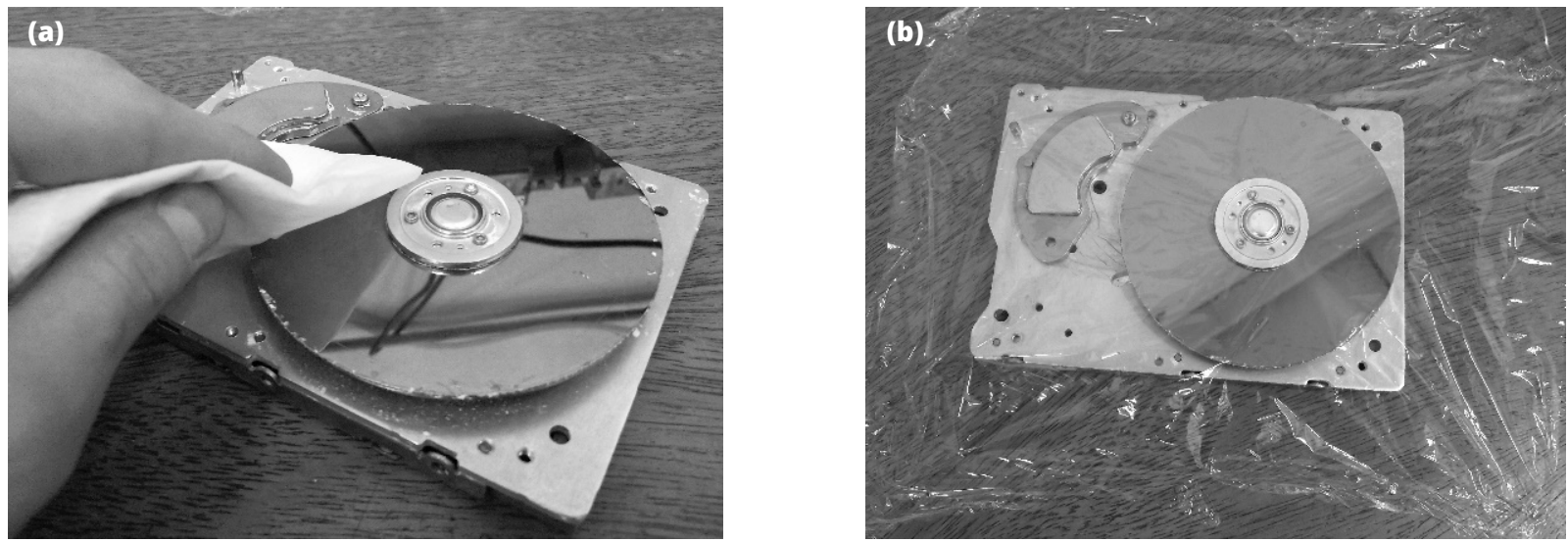

Figure 6: (a) Surface moistened; (b) surface covered by plastic foil.

The plastic foil was cut at the edges of metallic disk (Fig. 7a), then the disk was placed into a flask and a doublesided tape was placed on the motor shaft (Fig. 7b).
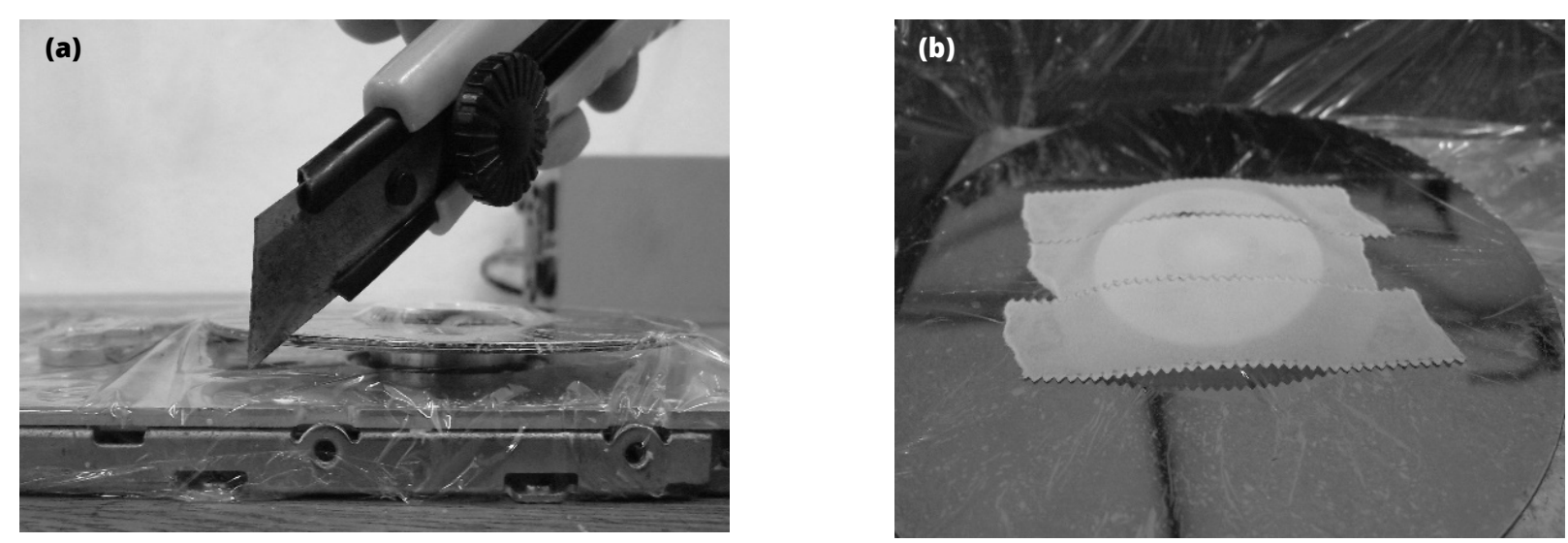

Figure 7: (a) Cut of plastic foil at the edges of disk; (b) double-sided tape on the motor shaft.

Then, glass blade (previously cleaned with current water and common detergent) was placed on the motor shaft (held by double-sided type) (Fig. 8a), and the PVA solution was deposited through a pipette covering all surface of glass (Fig. 8b). 

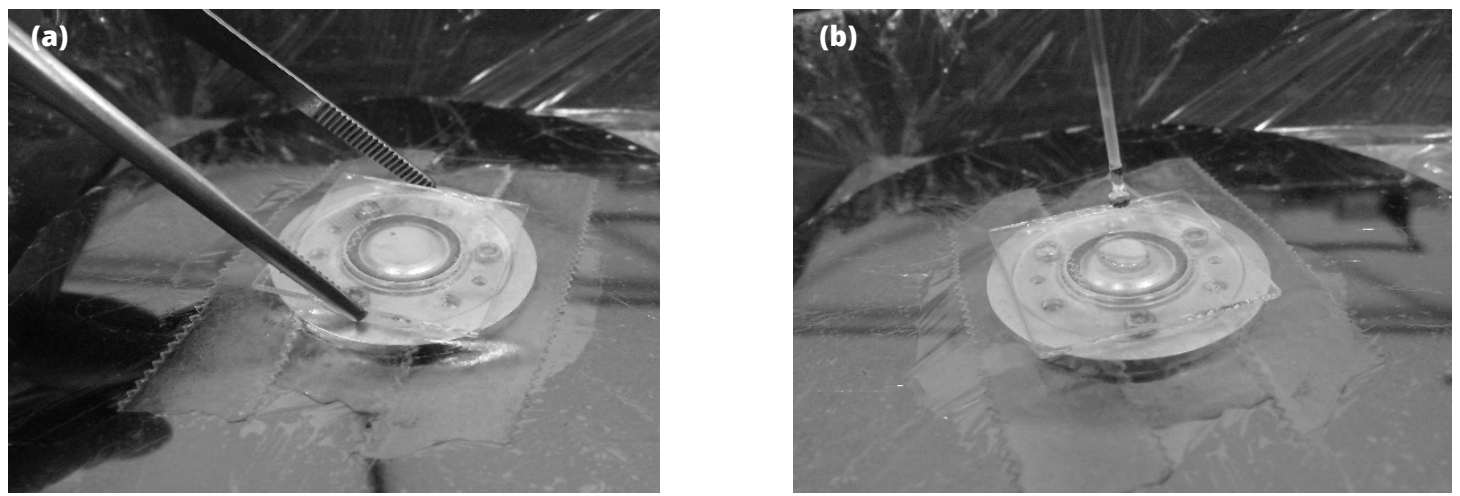

PVA: polyvinyl acetate.

Figure 8: (a) Glass blade on the motor shaft; (b) deposition of solution (PVA and methyl alcohol).

The deposition of PVA solution must be fast, due to the fast evaporation of methyl alcohol. Then in the spin-coating technique the speed of 5,400 rpm by 5 seconds was used. After that, the same rotation was used by 30 seconds (limited by electronic circuit board of hard disk) for the deposition of $\mathrm{CaO}$ powder. It was spread on the PVA thin film with glass substrate in movement, and the powder excess was projected-off the surface of the glass blade. Three or four depositions were sufficient to obtain good uniformity from the CaO layer. Figure 9A shows the appearance of the final process and Fig. 9B the nitrogen gas jet that was applied to remove the excess of material on the glass blade.
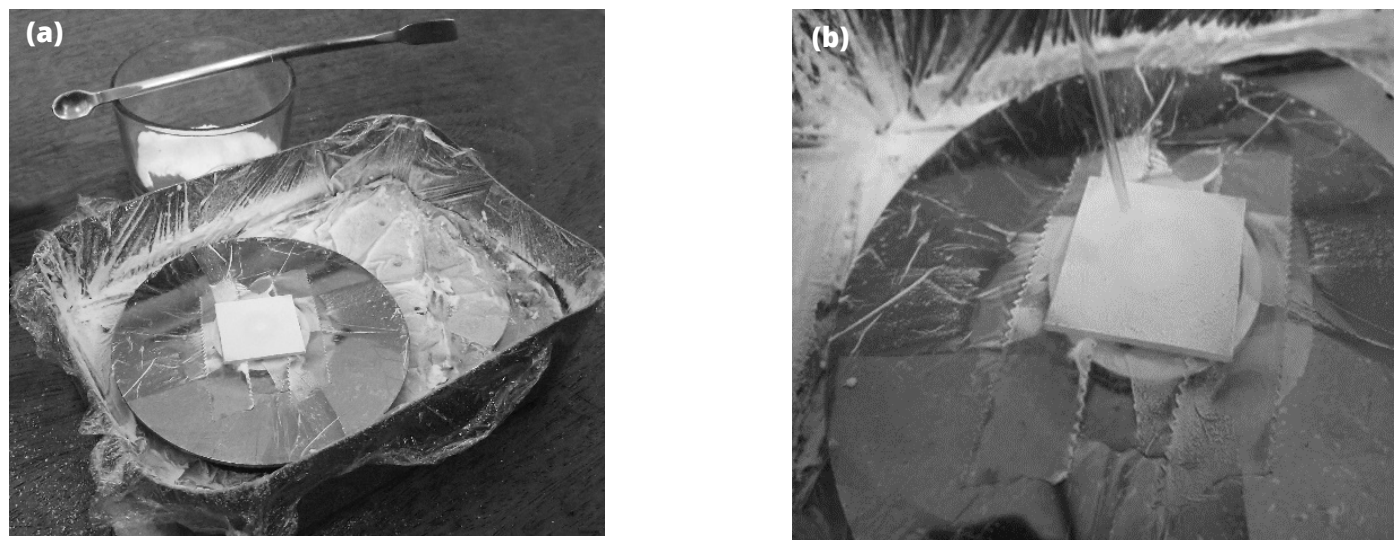

CaO: calcium oxide

Figure 9: (a): Thin film formed; (b): nitrogen jet to remove the CaO excess.

Then, a stripe of 2 to $3 \mathrm{~mm}$ of $\mathrm{CaO}$ was removed, as showed in Fig. 10, and a thin epoxy layer was applied at the edges of glass blade forming a solid elevation (after cure time). In literature, some references recommend a creation of distance between the active area of OLED device and encapsulation glass ${ }^{28,29}$. In the last procedure, the residual adsorbed moisture in secant layer was removed into vacuum oven with temperature at $60^{\circ} \mathrm{C}$ by 60 minutes.

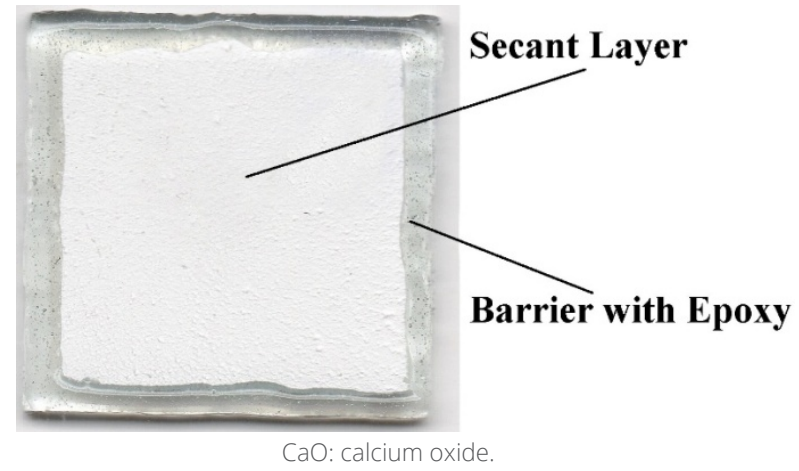

Figure 10: $\mathrm{CaO}$ powder removed at the edges and applied epoxy. 


\section{Preparation of PEDOT:PSS thin films}

To analyze the structure performances in relation to the permeation of moisture and oxygen from the atmospheric air, PEDOT:PSS polymeric thin layers were deposited between anode and cathode electrodes of indium tin oxide (ITO) thin films deposited on glass substrates, and this region was encapsulated with structure. For the formation of pads, the ITO thin film was corroded with zinc powder, hydrochloric acid $(\mathrm{HCl})$ and cotton. In deposition of PEDOT:PSS thin films, the spin-coating technique with 1,880 rpm by 30 seconds was used, and the solvent (water) was dried in an oven at $55^{\circ} \mathrm{C}$ by 20 minutes. To obtain the PEDOT:PSS layer only on the center of the sample, connecting anode and cathode, it was corroded with cotton and deionized water. Then, the structure was put on the PEDOT:PSS thin film, covering it completely. Figure 11A shows the geometry of the ITO on the glass substrate obtained and Fig. 11B the PEDOT:PSS on the center of the sample deposited.

(a)

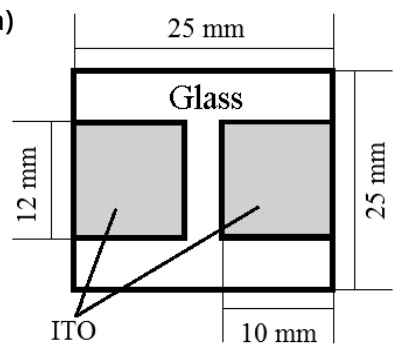

(b) PEDOT:PSS

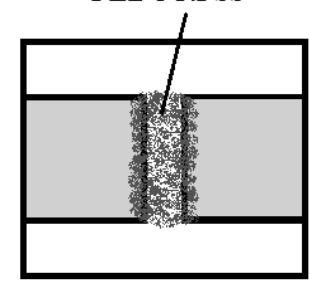

ITO: indium tin oxide.

Figure 11: (a): ITO electrodes on glass substrates; (b): PEDOT:PSS deposited between electrodes.

Another important procedure carried out is related with the electrical cords connected by multimeter with anode and cathode to obtain electrical resistance of the PEDOT:PSS layers. The cords were kept immobile during experiments, to avoid possible changes in the values measured carried out by elapsed days. The analyses were carried out using two different procedures involving seven samples.

In procedure 1, two samples were encapsulated inside glove box under nitrogen atmosphere and two were not. Then, encapsulated and unencapsulated samples were measured from initial to seven days (with seven measurements), and from initial to 25 days (with seven measurements).

On the other hand, in procedure 2, the first blade was encapsulated with structure; the second blade was encapsulated, but without secant; and the third blade was not encapsulated. The samples were measured from initial to seven days (with seven measurements). In the experiment carried out inside the glove box under nitrogen atmosphere, the space created between the secant and the PEDOT:PSS thin film was filled by nitrogen gas, while in the experiment carried out at ambient it was filled by atmospheric air (the atmospheric air presents $21 \%$ of oxygen and variation from 0 to $100 \%$ of relative humidity depending on the globe region) $)^{30,31}$.

The electrical measurements for both procedures were taken at atmospheric air, and the temperature and relative humidity of atmospheric air were measured during all analyses. Figure 12a shows the PEDOT:PSS thin film covered by structure with cord connections of multimeter to anode and cathode and Fig. 12b the cross section of all arrangement.
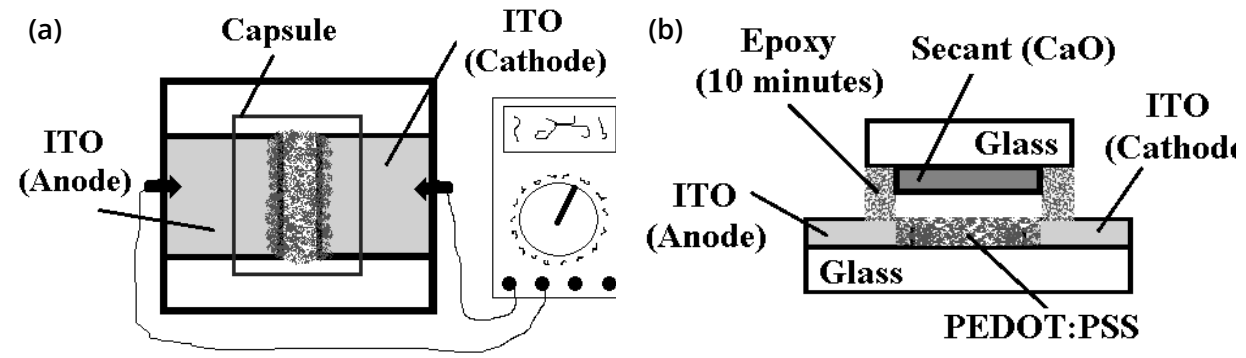

ITO: indium tin oxide; CaO: calcium oxide.

Figure 12: (a) Electrodes connected by multimeter to measure the electrical resistance; (b) cross section of arrangement with capsule and deposition of the PEDOT:PSS between ITO electrodes. 


\section{RESULTS}

The results showed a better understanding of PEDOT:PSS behavior in particular aspects related to the degradation by exposure to oxygen and moisture from atmospheric air directly influencing the electrical resistance of thin films.

The procedure 1 revealed for encapsulated and unencapsulated samples measured by different elapsed days a considerable increase of electrical resistance for samples without encapsulation. Figures 13a and 13b show the electrical resistance comparing encapsulated and unencapsulated samples measured by elapsed days. From the first day, it was possible to verify an elevation of the electrical resistance for unencapsulated sample, while the encapsulated sample showed the electrical resistance with linear aspect and this behavior shows good efficiency of the structure proposed.

In Fig. $13\left(\right.$ a) the room temperature was from 19.8 to $23.1^{\circ} \mathrm{C}$ and the relative humidity of atmospheric air was from 52 to $64 \%$, and in Fig. 13 (b) the room temperature presented was from 20.9 to $23.1^{\circ} \mathrm{C}$ and the relative humidity of the atmospheric air was from 50 to $61 \%$. Both low variations represent no significant influences on direct electrical resistance obtained, once the degradation caused by oxygen of air was most aggressive to PEDOT:PSS.

The results of procedure 1 showed a difference in the range values of the electrical resistance obtained for all samples analyzed by different conditions for seven and 25 days. This electrical characteristic can be attributed by different distances used with the alligator clip on the ITO thin film and also the different geometry formed of PEDOT:PSS on the surface of ITO anode and cathode.
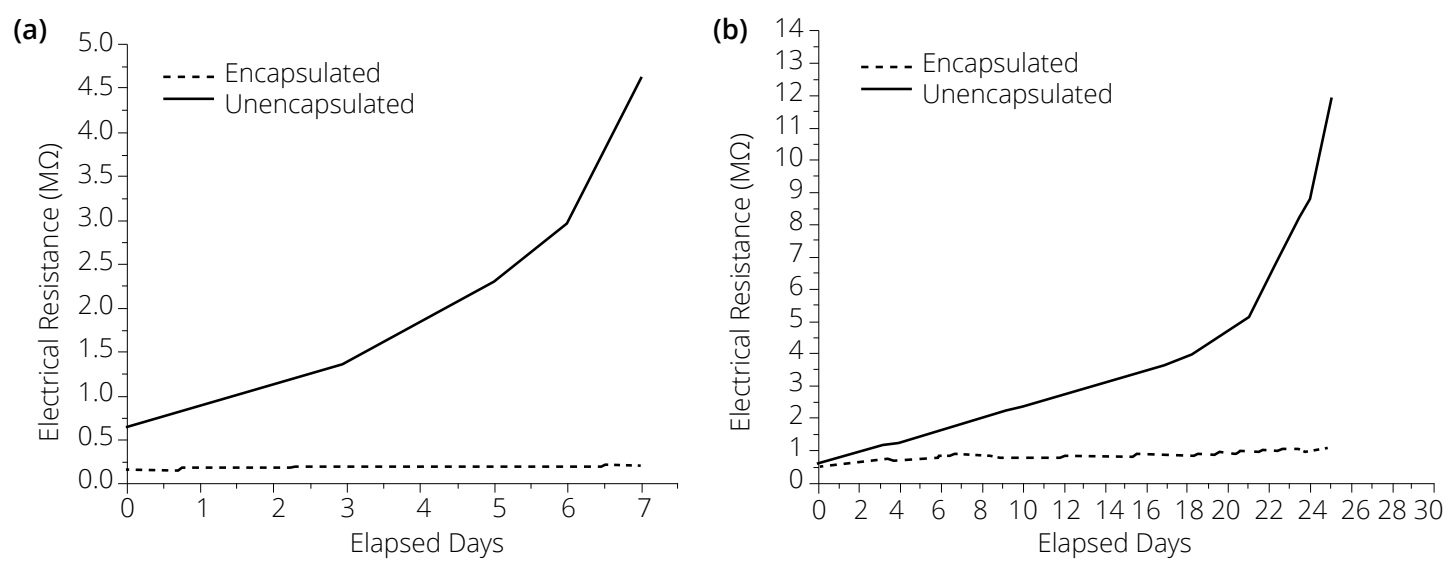

Figure 13: Procedure 1. (a) Electrical resistance vs. elapsed days for encapsulated and unencapsulated samples both measured by seven times from 0 (initial) to seven days; (b) electrical resistance vs. elapsed days for encapsulated and unencapsulated samples both measured by seven times from 0 (initial) to 25 days.

The procedure 2 revealed different behaviors of the electrical resistance for each sample measured in distinct conditions. In this case, the unencapsulated sample showed similar behavior for samples of procedure 1, presenting significant degradation of PEDOT:PSS layer and considerable increase of the electrical resistance. In the PEDOT:PSS layer covered, the glass blade used as a barrier to degradation promoted no protection, but this performance was smaller if compared with the sample used in the structure proposed. Figure 14 shows the performance of the samples used in the procedure 2 .

It is very important to report that during the acquisition of results in the procedure 2 the average temperature obtained was $21^{\circ} \mathrm{C}\left( \pm 1^{\circ} \mathrm{C}\right)$ and the relative humidity of atmospheric air was $56 \%( \pm 4 \%)$. This little variation for both procedures ( 1 and 2 ) demonstrates some influences on the electrical resistance, especially for unencapsulated samples.

The procedure 2 also revealed a very expressive increase of the electrical resistance for unencapsulated sample, as occurred in the procedure 1 . The results compared between the sample encapsulated only with glass and the sample encapsulated with structure showed variation in the electrical resistance values that can be attributed to the secant use. The fact of the sample was encapsulated represents a good performance when compared with unencapsulated samples, as observed in Fig. 14. 


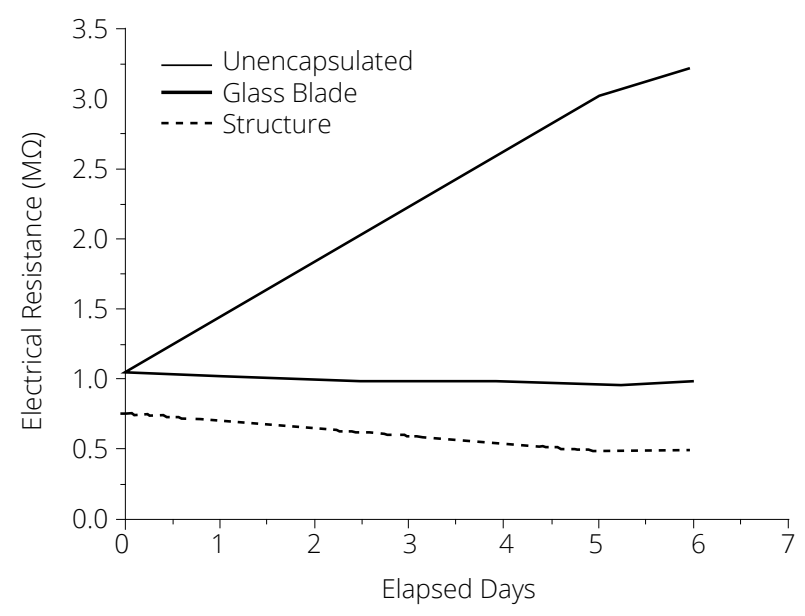

Figure 14: Procedure 2: electrical resistance vs. elapsed days of the samples measured using three different methods.

\section{CONCLUSIONS}

Considerable increase of lifetime for OLED devices mounted at laboratory can be achieved applying some techniques of encapsulation, and in this work an easy method was demonstrated. The encapsulation process makes the OLED mounted at laboratory be polarized by sometimes showing the real potential of materials used and the real performance achieved by the device. OLED devices without encapsulation are possible only to obtain two or three polarizations with considerable decrease of electrical current and luminance and increase of the threshold voltage caused by degradation of the organic materials used.

In this work, it was proposed an encapsulation method analyzing PEDOT:PSS polymeric thin films that are very sensitive to the chemical attack caused by moisture and oxygen from atmospheric air. The method to decrease the degradation process was composed by low-cost materials: glass, epoxy, glue and CaO as secant to form the structure. These materials together showed to be the most effective method of encapsulation when compared with unencapsulated samples or another method that only uses glass with epoxy. The analyses revealed lowest electrical resistance of PEDOT:PSS thin films encapsulated with complete structure by elapsed days. For this reason, this encapsulation method is suggested to be applied in the assembly of OLED devices in laboratory.

\section{AUTHOR'S CONTRIBUTION}

Conceptualization: Santos ER, Yuki EY, Shu Hui W; Data Curation: Yuki EY e Santos ER; Formal Analysis: Yuki EY e Santos ER; Funding Acquisition: Santos ER, Yuki EY, Shu Hui W; Methodology: EYuki EYrik e Santos ER; Resources: Santos ER, Yuki EY, Shu Hui W; Software: Shu Hui W; Supervision: Santos ER; Validation: Santos ER; Visualization: Yuki EY e Santos ER; Writing - Original: Yuki EY e Santos ER; Draft Preparation: Yuki EY e Santos ER; Writing - Review \& Editing: Yuki EY e Santos ER

\section{DATA AVAILABILITY STATEMENT}

Data are available in a data repository.

Yuki E. Estudo de encapsulamento de dispositivos poliméricos orgânicos eletroluminescentes [undergraduate thesis]. São Paulo: Escola Politécnica da Universidade de São Paulo; 2011. 


\section{FUNDING}

Coordenação de Aperfeiçoamento de Pessoal de Nível Superior

[http://doi.org/10.13039/501100002322]

PNPD Project Nº2998/09-2

\section{ACKNOWLEDGMENTS}

The authors thank the Escola Politécnica da Universidade de São Paulo, Engenharia Metalúrgica e de Materiais, for providing installations and equipments.

\section{REFERENCES}

1. Universal Display Corporation. OLED Investor Presentation. 2Q Power Point Presentation. Universal Display Corporation; 2020.

2. Boroson M. OLED Light Extraction Status and Needs. OLED Works naturally Illuminating Power Point Presentation. In: Annals of the DOE SSL R\&D Workshop; 2020; San Diego; 2020.

3. Ricks M. OLED solutions for lighting applications, Advanced Materials for Next Generation OLEDs. Merck KGaA, Darmstadt, Germany, Performance Materials. In: Annals of the DOE SSL R\&D Workshop; 2020; San Diego; 2020.

4. Ansari SP, Ali F. Conjugated Organic Polymers for optoelectronic Devices. Functional Polymers. 2019;9:749-88. https://doi.org/10.1007/978-3-319-95987-0_21

5. Adachi C, Sandanayaka ASD. The Leap from Organic Light-Emitting Diodes to Organic Semiconductor Laser Diodes. CCS Chemistry. CCS Chem. 2020;2(4):1203-16. https://doi.org/10.31635/ccschem.020.202000327

6. Annals of the 46th Annual National Inventors. Hall of Fame. 2018 Induction Ceremony. Honoring the greatest Innovators; 2018.

7. Huang Y, Hsiang E-L, Deng M-Y, Wu S-T. Mini-LED, Micro-LED and OLED displays: present status and future perspectives. Light Sci Appl 2020;9:105. https://doi.org/10.1038/s41377-020-0341-9

8. Lindén J. OLEDs: State of the art report: Up-to-date and characterization [Internet]. Denmark: Technical University of Denmark; 2019 [cited on Feb. 2021]. Available from: https://orbit.dtu.dk/en/publications/oleds-state-of-theart-report-up-to-date-and-characterization

9. Lochner C. Printed Organic Light Emitting Diodes for Biomedical Applications. Electrical Engineering and Computer Sciences. Technical Report No. UCB/EECS-2020-31 [Internet]. Berkeley: University of California; 2020 [cited on Feb., 2021]. Avaliable from: https://www2.eecs.berkeley.edu/Pubs/TechRpts/2020/EECS-2020-31.pdf

10. Corsini F, Griffini G. Recent progress in encapsulation strategies to enhance the stability of organometal halide perovskite solar cells. J Phys Energy. 2020;2(3):031002. https://doi.org/10.1088/2515-7655/ab8774

11. Park KW, Lee S, Lee H, Cho Y-H, Park YC, Im SG, et al. High-performance thin H:SiON OLED encapsulation layer deposited by PECVD at low temperature. RSC Adv. 2019;9:58-64. https://doi.org/10.1039/c8ra08449a

12. Wu J, Fei F, Wei C, Chen X, Nie S, Zhang D, et al. Efficient multi-barrier thin film encapsulation of OLED using alternating Al2O3 and polymer layers. RSC Adv. 2018;8:5721-7. https://doi.org/10.1039/c8ra00023a

13. Yuki E. Estudo de encapsulamento de dispositivos poliméricos orgânicos eletroluminescentes [undergraduate thesis]. São Paulo: Escola Politécnica da Universidade de São Paulo; 2011.

14. Santos G. Estudo de dispositivos orgânicos emissores de luz empregando complexos de terras raras e de metais de transição [thesis]. São Paulo: Escola Politécnica da Universidade de São Paulo; 2008. 
15. Osram. Introduction to OLED Technology. Catalogue [Internet]. Osram; 2014 [cited on Feb. 2021]. Available from: http://www.osram.com/media/resource/hires/335716/introduction-to-oled-

16. Tominetti S, Gigli J, Shih S-H, Su Y-T, Jou JH. Seal Encapsulation: OLED Sealing Processes. In: Handbook of Organic Light-Emitting Diodes. Springer; 2018. p. 1-31. https://doi.org/10.1007/978-4-431-55761-6_23-1

17. Moro L, Visser RJ, MacDonald B, Kumar SR, Rosenblum MP, Morrison N, et al. Barrier Film Development for Flexible OLED. Handbook of Organic Light-Emitting Diodes. In: Handbook of Organic Light-Emitting Diodes. Springer; 2018. p. 1-37. https://doi.org/10.1007/978-4-431-55761-6_25-1

18. Yan M, Kim TW, Erlat AG, Pellow M, Foust DF, Liu J, et al. A Transparent, high barrier, and high heat Substrate for organic Electronics. Proceedings of the IEEE Xplore. 2005;93(8):1468-77. https://doi.org/10.1109/ JPROC.2005.851483

19. Charton C, Schiller N, Fahland M, Holländer A, Wedel A, Noller K. Development of high barrier films on flexible polymer substrates. Thin Solid Films. 2006;502(1-2):99-103. https://doi.org/10.1016/j.tsf.2005.07.253

20. Li Z, Meng H. Organic light-emitting materials and devices. New York: Taylor \& Francis; 2006.

21. Wang D, Cheng C, Tsuboi T, Zhang Q. Degradation Mechanisms in Blue Organic Light-Emitting Diodes. CCS Chemistry. 2020;2(4):1278-96. http://doi.org/10.31635/ccschem.020.202000271

22. Santos G, Cavallari MR, Fonseca FJ, Pereira L. Oxygen Plasma Surface Treatment onto ITO Surface for OLEDS Based on Europium Complex. I Integrated Circuits Syst [Internet]. 2015 [cited on Feb. 2021];10(1):7-12. Available from: https://www.sbmicro.org.br/jics/html/artigos/vol10no1/1.pdf

23. Su S-H, Huang C-Y, Wu C-M, Huang C-P, Lin Y-S. Enhancing the lifetime of flexible organic light emitting diodes by encapsulation technique. Int J Eng Res Appl. 2020;10(9):51-5. http://doi.org/10.9790/9622-1009035155

24. Fullenbach TC. Estudo de Diferentes TCOs utilizados como eletrodos anodos em dispositivos OLEDs [Bachelor in Microeletronics]. São Paulo: Faculdade de Tecnologia de São Paulo; 2019.

25. Daniela Diodato de Magalhães DD. Encapsulamento de dispositivos poliméricos emissores de luz [undergraduate thesis]. São Paulo: Escola Politécnica da Universidade de São Paulo; 2009.

26. Ohashi S, Baba E, Okuno M, Hosoi M, Shindo Y, Takada M. High-Transparency Adhesive-Encapsulation Film for OLED Device. Wiley Online Library. 2020;51(1):1036-9. https://doi.org/10.1002/sdtp.14050

27. Santos ER, Wang SH, Correia FC, Costa IR, Sonnenberg V, Burini Junior EC, et al. Influência de diferentes solventes utilizados na deposição de filme de poli(9-vinilcarbazol) em dispositivos OLEDs. Quím Nova. 2014;37(1):1-5. https://doi.org/10.1590/S0100-40422014000100001

28. Gärditz C. OLED Technology Introduction. OLED Application Engineering [Internet]. Osram [cited on Feb., 2021]. Available at: https://docs.rs-online.com/bdba/0900766b80e9a86a.pdf

29. ParkJ-S, Chae H, Chung HK, Lee SI. Thin film encapsulation for flexible AM-OLED: a review. Semicond Sci Technol. 2011;26:034001. https://doi.org/10.1088/0268-1242/26/3/034001

30. Nasa. Global Climate Change. 10 interesting things about air. Air is mostly gas [Internet]. Nasa; 2016 [cited on Oct. 25, 2020]. Available from: https://climate.nasa.gov/news/2491/10-interesting-things-about-air/

31. Nasa. Relative Humidity in the Upper Troposphere [Internet]. Nasa [cited on Oct. 25, 2020]. Available from: https://earthobservatory.nasa.gov/images/4312/relative-humidity-in-the-upper-troposphere 